\title{
Introduction: happiness, economics and politics
}

\section{Amitava Krishna Dutt and Benjamin Radcliff}

The nature and meaning of happiness has been discussed over the centuries by religious figures, philosophers and, more recently, by social scientists. Moreover, it seems indisputable that happiness has always been the (or at least, a) goal of, or driving force for, most human beings. In recent years a new field of inquiry, the so-called 'science of happiness', has emerged. This field tries to examine the idea of happiness using quantifiable and measurable concepts and to analyse its determinants using the empirical and theoretical tools of the social and biological sciences.

The 'scientific' study of happiness, however, has been conducted by scholars from different disciplines in different and largely separate ways. Psychologists have turned from an emphasis on problems such as depression to a consideration of positive affect, and attempted to measure a number of notions of happiness using survey and experimental data, as well as brain signals, and have focused on different kinds of mental processes, personality traits and environmental factors to understand the determinants of happiness. Economists have focused on the effects of income and consumption on happiness and well-being, debating, essentially, whether money buys happiness. They have also approached the study of economic development using the concepts of economic growth and improvements in well-being. Sociologists have emphasized interactions within communities, families and groups as well as the broader effects of culture on happiness. Political scientists have focused on how different systems of government - such as democracies - and different types of governmental policies, such as the size of the welfare state, affect happiness. Philosophers have speculated on the meaning of happiness - for instance, whether it involves the maximization of pleasure, the minimization of pain, or maximization of the difference between pleasure and pain, or whether it refers to human flourishing. There have, of course, been scholars who have crossed the normal boundaries of their own disciplines to incorporate factors from outside. For instance, some economists - such as Veblen (1899) and, more recently, Schor (1998) and Frank (1999) - have incorporated ideas about 
status, more traditionally studied by sociologists, in analysing the relation between consumption and happiness, while some political scientists - such as Lane (2000) and Putnam (2000) - have addressed issues related to friendship and community in understanding the determinants of happiness. But the general tendency, given the disciplinary structure of the academy, has been to remain largely within a particular discipline.

As students of happiness and well-being, we believe that the study of happiness is best done from a multidisciplinary perspective, and that to make progress in the subject we need greater communication and interaction among different disciplines. We therefore decided to organize a conference with scholars from different disciplines, including history, psychology, philosophy, sociology, economics and political science. Coming ourselves from economics and from political science, we are especially interested in how concepts and issues in economics and political science can be combined and cross-fertilized to deepen our understanding of happiness. Therefore, although we sought representation from a variety of disciplines, we invited more scholars from our two disciplines than from the others.

This book contains versions of most of the papers presented at the conference, as well as our own reflections based on our own work and the proceedings of the conference. The book is divided into four parts, the first on happiness in general, the second on economics and happiness, the third on politics and happiness, and a final one on what is to be done. The following sections of this introduction discuss some of the key questions related to each part and how the chapters in this volume relate to these questions. Thus, the next section provides a general introduction to the history, conceptualization, theories and empirics of happiness. The following two sections then examine, in turn, the relationships between happiness, and economics, and politics. The subsequent section argues that an interdisciplinary perspective is necessary for obtaining a better understanding of happiness and its determinants, and focuses on the interaction between economic and political factors in explaining happiness. The final section discusses some implications of the analysis for what can and should be done, individually and collectively, for improving human well-being and making people happier.

\section{I.1 HAPPINESS}

Like most genuinely great ideas, happiness has successfully resisted attempts to be reduced to any single meaning or definition. We begin, thus, with an appraisal of what happiness is, and how best we might conceive of 
it not merely as philosophers, but also as scholars of the empirical, observable world. The volume thus begins with Darrin McMahon's insightful discussion of Western attitudes to the meaning of happiness and the possibility of its attainment, a discussion which he has carried out at much greater length in his book on the history of happiness (McMahon, 2006). Early on, happiness was considered a matter of luck, or something that was not achievable in the here and now, at least by more than a handful of people. He argues that the notion of happiness being our being's ends and goal is an Enlightenment creed which has crowded out other ways of looking at the world and human purpose in it. McMahon sees the triumph of this Enlightenment creed as a larger dynamic which explains the wide contemporary appeal of happiness studies. But, he argues, happiness studies would do well to be cognizant of this history of happiness. Thus, McMahon 'enter[s] a humble plea as a historian and scholar of the humanities for a certain humility as we approach our subject, pointing out the un-nerving tendency of happiness to frustrate and circumvent those who would try to grasp it in pursuit'.

The need for that humility is readily seen in any survey of the meaning of happiness. We see a concern with happiness in the earliest philosophers and religions in both the East and the West. For instance, the ancient belief systems of India, which are now collectively referred to as Hinduism, took the view that 'true' happiness requires the realization of a person's oneness with Brahman, the universal soul, and the liberation from worldly desires. Buddhism also stressed the importance of overcoming desire and of avoiding extremes of pleasure and austerity, of following 'the middle path'. The major Greek philosophers did not especially value everyday sensual pleasures, with Plato favoring the controlling of appetites rather than being enslaved by them, and Aristotle valuing fulfilling activities which led to eudaimonia or flourishing, exemplified at the highest level by intellectual contemplation. Christianity, Judaism and Islam regard happiness as the goal of religious life and beliefs to be attempted through knowing and serving God. However, true happiness, they imply, can only be achieved in afterlife, in the form of union with God. Later Christian philosophers, like St Thomas Aquinas, tried to synthesize the Aristotelian view about happiness in this world and the early Christian view that true happiness can only be achieved in afterlife by suggesting that happiness in this life, while imperfect, can approximate the true happiness of afterlife through virtuous living.

With the weakening of the hold of religion in everyday life and general secularization that accompanied the Enlightenment and the Industrial Revolution, it came to be increasingly accepted that happiness is something that all people could at least aspire to in their lives on earth. However, a 
variety of meanings was attached to happiness by philosophers. Some, such as the Utilitarians, emphasized that increasing happiness entailed that we take seriously the seemingly mundane observation that we should increase pleasure and decrease pain. Others, such as Schopenhauer, were closer to Eastern traditions by focusing mostly on minimizing pain, while still others, such as Nietzsche - and creative writers such as Joyce - emphasized the maximization of pleasure, the pursuit of 'passionate joy', whatever the potential price to be paid.

Many social scientists, instead of trying to define happiness in these ways, rely on asking people how happy they actually feel. There is a large amount of survey data now available which asks people to report on, say, on a 10-point scale, how happy or satisfied they are with their lives, all things considered. This approach in effect allows subjects to decide what they mean by happiness, and lets them decide how happy they are given their own definition. This approach to happiness is often referred to as subjective well-being, in an effort to apply a more precise and less emotionally laden term than happiness. While some have argued that such measures are valid and reliable, and that levels of subjective well-being and how they change over time and place can tell us about the objective conditions that make people better off, others remain skeptical, because of cultural differences across people and because people are known to adapt to their environments. Thus, different cultures can interpret happiness and its desirability differently, and the poor can get used to their destitution and feel reasonably happy.

Despite the growing popularity of measures of subjective well-being, social scientists have continued using less subjective measures of happiness and well-being. Thus, psychologists distinguish between different levels of happiness, a first referring to (transient) emotions and feelings of joy and pleasure, a second to people's judgments about their feelings over a long period of time (that is, subjective well-being), and a third to whether one fulfills one's true potential, or whether one flourishes, and is closer to the Greek notion of the good life or eudaimonia (see, for instance, Nettles, 2005). In his contribution to this volume, Anthony Ong argues that developments in the psychology of happiness and well-being suggest that wellbeing cannot be well represented by a single dimension, so that researchers have to examine both eudaimonic and hedonic aspects of happiness and well-being to obtain a more complete understanding of positive human health. Ong points out that current psychological research measuring wellbeing takes two major alternative paths. One measures subjective wellbeing, which involves a person's cognitive judgment of life satisfaction, and an emotional aspect consisting of independent positive and negative affect components. The other derives from eudaimonic expressions of 
virtue, and the striving for the realization of one's true potential, and is measured by the concept of psychological well-being, involving different aspects of human actualization, such as autonomy, personal growth, life purpose and social connectedness. Ong then discusses methods with which it is possible to examine the relationship between these two aspects of well-being, and how this varies within persons (with most of the current research examining variations across persons for a single aspect). He examines methods involving longitudinal panel designs and intensive bursts designs, as well as less widely used growth curve modeling and dynamic systems analysis using differential equations, and explores how these methods can deal with rounded and irregular structures (rather than rectilinear systems) necessary for understanding the complexity of the human brain. While this work, like McMahon's, tells a cautionary tale in how readily we are willing to accept the conventional, mainstream use of survey-based indicators of happiness or life satisfaction, much of the rest of the chapters in this volume, reflecting the norms of the literature, do rely upon fairly straightforward measures of well-being.

Economists, while strongly wedded to the notion of utility and its maximization by economic agents as the method of explanation behavior and evaluating states in terms of individual utility (which may be measured with subjective well-being surveys), often rely more heavily on real income and production as measured by the national accounts because of their relative ease of measurement, assuming that more (in terms of products and income) is better (in terms of utility or happiness). Moreover, recognizing that people adapt to their states in terms of subjective feelings (like the poor person getting used to poverty), some economists (see especially Sen, 1999) favor less subjective concepts such as functionings (whether people are able to achieve particular good results in terms of things - such as good health, adequate nutrition and even adequate self respect - that are considered valuable) or capabilities (whether people have the opportunity to achieve these functions, rather than whether they actually achieve them).

Turning from the meaning of happiness to theories of happiness, in the social scientific literature on subjective well-being, three broad kinds of theories have emerged for predicting how happiness varies across countries or individuals. Using the terminology suggested by Veenhoven and Ehrhardt (1995), and further elaborated by Ruut Veenhoven in his contribution to this volume, one can think of theories focusing on (1) traits, (2) social comparisons or (3) satisfaction of needs.

Trait theories contend that happiness is a relatively fixed personality trait, similar to other aspects of personality, resulting from a combination of genetic inheritance, cultural socialization and other early life experiences. Individuals, then, tend toward a basic level of happiness, 
in the same way that they tend toward a certain level of extroversion or optimism. Psychologists often think thus in terms of 'set-points' to which individuals are prone. Life events may move them to either more or less happiness, but such changes tend to be temporary, with individuals eventually returning to something like their original set points over time. The same logic applied to the national level suggests that people in some countries just naturally tend to be happier than those in others, as a part of the national character - that is, a national set-point, reflecting a kind of national personality.

Comparison theories, often favored by economists such as Easterlin (1974), are predicated upon the notion that individuals appraise the quality of their lives in relative rather than absolute terms. In it simplest incarnation, people look to society's 'consumption norm', and evaluate their lives relative to that norm, such that those with a higher level of consumption view themselves as more satisfied, and those below, less so. The obvious conclusion is that, presuming the consumption norm is society's median, the mean level of happiness will everywhere be the same, and will not change significantly over time (since, of course, raising the social median level of consumption cannot change the fact that there are always as many people above it as below it). There are more complicated and sophisticated notions of relativity (as reviewed by Diener et al., 1999), but all depend upon the fundamental notion of comparing one's position (typically in terms of income, social status or other measures of consumption) against some external standard.

Both trait and comparison theory, then, stand in contrast to what Veenhoven has rightly characterized as the 'common sense' view that satisfaction with life is determined by the amount of needs that one's life circumstances allow to be meet. Thus, following the conventional idea of a hierarchy of needs (Maslow, 1954), the more needs that are met, the more rewarding and fulfilling one is likely to find life. Veenhoven's contribution to this volume continues his work in evaluating trait and comparison theories, and in articulating and defending the needs-based theory. As his chapter notes, the stakes involved in which theory we find most compelling are enormous, in that trait and comparison-based theories tend toward the view that national levels of happiness simply cannot be lastingly improved, since if happiness is a trait, levels will return to their set-points whatever interventions we make in the world to make life more secure or otherwise enjoyable, and if happiness is relative, these same kind of changes will merely raise the consumption norm, and thus leave the overall level of happiness unchanged. In sum, how we theorize about happiness determines whether it is sensible to even try to improve living conditions across the world, given that both trait and comparison theory suggest that doing 
so will not increase the amount of actual happiness in the world. We return to this issue in the conclusion of this book.

The set-point notion of happiness, of course, need not lend itself to the conclusions Veenhoven sees when applied at the purely individual level (and hence even over aggregates). Thus, one can posit that people do have set-points, perhaps even as a hardwired, genetic aspect of a personality, while admitting that individuals might be able to reprogram themselves for greater happiness by using their power of agency to play against a reversion to set-point (that is, 'adaptation'). This may be of scant comfort to those of us, like Veenhoven, concerned with the possibility of using public policy to improve objective living conditions, and thus, subjective appraisal of life (given that a country's 'national character' as expressed by its cultural norms can hardly be consciously reprogrammed), but it does open the door to specific strategies individuals may use in their day-to-day lives to make life more satisfying. It is this very possibility that has given rise to the 'positive psychology' movement. In their contribution to this volume, Kennon Sheldon and Sonja Lyubomirsky provide an overview of one of the most promising developments in that field in the form of the 'Sustainable Happiness Model'. They grant that one's happiness is largely determined by genetics and other circumstantial factors beyond the individual's control, but also argue that one's activities also play a role, such that the set-point should be construed 'as a range' so that it is possible 'to construct one's life in such a way that one stays in the upper half of one's set range, finding ways to remain at a level of happiness that is higher than one's genetics alone would dictate'.

Proponents of the comparison theory, also, do not argue that happiness levels cannot change over time and space. Even if for some things, like income and consumption, people obtain happiness mainly from what they have in comparison to others, rather than from their absolute levels, it does not follow that all things on which individual happiness depends involve such comparisons. For instance, individual happiness may depend strongly on absolute levels of leisure, time spent with family and friends, good health and a clean environment. Indeed, as we shall discuss later, they argue that individuals actually devote too much effort in obtaining things involving comparisons (to get ahead of others) and too little on things that do not involve comparisons.

A final theoretical distinction in the study of happiness relevant to our concerns is the distinction between global evaluations of life in general, which is the principal focus of most research, and the evaluations of happiness with particular aspects, or 'domains', of life. In this latter interpretation happiness may be defined as the feeling one gets by being with one's family, having better health, having a rewarding job or having more 
money. This observation also suggests empirical analysis of what actual conditions determine overall happiness. There is considerable literature examining the determinants of happiness, more specifically, exploring how happiness depends on personal factors such as income, health conditions, whether one is employed, conditions of work, time spent with family and friends, status, religiosity, personality traits, age, marital status, gender and race, overall economic conditions such as inflation, unemployment and income distribution, overall political conditions such as nature of the government, trust in government and political instability, and other general factors like the weather (see, for instance, Argyle, 1987, 1999; Frey and Stutzer, 2002; Layard, 2005). In their contribution to this volume, Richard Easterlin and Onnichi Sawangfa bring these two strands of the literature together, and examine how trends in overall indicators of happiness relate to satisfaction people report from the widely discussed domains of finance, family life, work and health. They find that the importance of any given domain depends on actual life circumstances regarding socioeconomic status (as measured by years of schooling), time (year dummies), age or birth cohort, and that no individual domain is invariably the key determinant of overall happiness. This analysis also enables them to explain a number of empirical trends that have been found in the happiness data for the USA, that is, the positive cross-sectional relation between happiness and socio-economic status, the horizontal time series trend in happiness, the hill pattern of life cycle happiness and decline in happiness across generations.

\section{I.2 HAPPINESS AND ECONOMICS}

Of obvious relevance to economists is the question whether happiness increases when people consume more goods and services. It is widely believed by people that more is better and that money buys happiness. This belief is reflected in the theory used by mainstream economists, which assumes that individuals maximize utility, and that utility increases with the individual's consumption or income without bound (although there may be diminishing marginal utility). It is also reflected in the way mainstream economists usually evaluate states of the economy using the notion of efficiency. Although efficiency is formally described as a situation in which no one can be made better off without making someone else worse off, in actual applications the concept is usually taken to require that there is production efficiency, that is, the economy cannot produce any more of any good or service without reducing the production of something else: everything has an opportunity cost. Economists also typically equate economic development 
with the growth of per capita income or product, and even when they take equity or distributional issues into account, they usually measure inequality and poverty in terms of real income or consumption.

But is more really better as judged by the people who have more? Starting with Easterlin's (1973) pioneering contribution, some economists have found that happiness in the sense of subjective well-being doesn't seem to rise systematically with income (see Easterlin, 2001; Frey and Stutzer, 2002; Layard, 2005). Across countries most studies find that, at least beyond a certain level of income, happiness does not rise significantly with income. Time series data for rich countries, such as the USA and Japan, suggest that happiness does not increase over time despite significant increases in income. Individuals in rich countries who experience significant increases in time do not report significant increases in happiness. The only kind of empirical analysis that unequivocally supports the notion that more is better is cross-sectional analysis of individual countries: people with higher levels of income tend to be happier than those who are poorer.

What explains these empirical findings, which contradict some of the basic assumptions of many economists? Suitable answers have to explain both why people increase their income and consumption and why they are not happier as a result, a phenomenon that has been called the Easterlin Paradox. Economists have come up with a number of plausible explanations which can be classified into two groups. One group focuses on the individual decision maker and argues that for a variety of reasons individuals make poor decisions which make them consume more without becoming happier as a result. The other group examines the individual decision maker in a social context where, although in isolation they could make decisions which make them happier, such decisions are influenced by the behavior of others, and the actions of all individuals taken together result in conditions which make individuals not happier.

In the first group are explanations which focus on psychological processes involved in decision making and the feelings individuals experience after they make their decisions. Individuals make decisions to do certain things - like consuming more - but they make decisions which make them no happier because they either do not know what makes them happier, or because they do not have the willpower to do what makes them happier. In his contribution to this volume, Alois Stutzer uses the tools of happiness studies to examine whether individuals act 'rationally' in their self-interest, or whether they sometimes yield to temptation which overwhelms their willpower, resulting in outcomes that are not optimal for them. He examines this question by reviewing analysis and evidence on smoking and television viewing, and discusses his own recent work on obesity. He finds that 
individuals frequently report to being unhappy with their decisions about smoking, television viewing and eating, and their consequences, and this loss in happiness is positively related to their own judgments about their lack of self-control. Thus, when doing something leads to immediate (even minor) gratification, and the costs - even if well understood and significant - come later, individuals perform these activities. These findings go against one of the standard assumptions of neoclassical economics - that what people choose is the best for them because they choose 'rationally'.

In the second group are explanations which state that people, when interacting with others, make decisions which do not make them happier because they are influenced by the behavior of others, and because the feelings they experience after making their decisions are affected by what others do. For instance, following the work of Veblen (1899), Schor (1998) and Frank (1999) many others have argued that individuals try to consume more to increase their status in society, but if all of them do so, no one is better off. In fact, they may be worse off if their attempts to increase consumption result in their working more hours at the expense of leisure and time spent with friends and family, and their incurring more debt which makes them financially insecure. Increases in consumption over time can also result in higher levels of aspirations and social conventions about needs, so that there may be no increases in happiness (see Easterlin, 2001). Moreover, by increasing sales promoting expenditures, firms may influence consumers into buying goods which ultimately raise their expectations and do not make them happier. Such explanations are examples of what, following Veenhoven, was earlier referred to as comparison theory. However, this approach does not imply that happiness or well-being cannot depend on specific circumstances. Several of these arguments are closely related to the relative consumption hypothesis which states efforts by all to increase their consumption will lead to no significant changes in happiness since their relative consumption does not change.

The chapter by Amitava Dutt reviews different explanations about why people increase their consumption without experiencing increases in their happiness, and argues that the relative consumption effect, especially those operating through status-seeking and norm-based consumption, seem to have the widest applicability. This chapter also discusses a simple theoretical formulation of the relative consumption hypothesis and examines some implications of it, such as the role of religiosity in promoting happiness, to show that they are consistent with the empirical evidence. The analysis implies that, at least after a point, more need not be better.

It may be noted that, in addition to explaining why consumption may increase without increasing happiness, both of these groups of explanations have important and wide-ranging implications for the methodological 
underpinnings of mainstream or neoclassical economics. The first group questions a basic axiom of neoclassical economics, that is, economic actors are 'rational' optimizers. The second group questions the entire notion of efficiency, that is, the idea that more (goods and services) is better.

Beyond their interest in whether money buys happiness for individuals, economists are also concerned with how happiness and well-being depend on other macroeconomic factors, such as unemployment, inflation, income distribution and fairness, economic growth and the state of the environment. These relations are not only important in themselves for understanding what conditions make people better off, but also affect the relation between consumption and income, on the one hand, and happiness and well-being on the other. For instance, higher levels of individual consumption can collectively damage the environment which in turn may have a negative effect on happiness. Also, efforts by people to increase their consumption can lead them to support policies - such as less support for worker rights - that may worsen the distribution of income which may in turn reduce happiness. It is also possible that higher levels of consumption boost aggregate demand, increase output and reduce unemployment, thereby making people happier.

Two chapters in this book examine the relation between happiness and well-being and such aggregate conditions. Robert Frank examines whether, in light of the Easterlin Paradox which states that increases in income (at least beyond a certain point) do not increase happiness, economic growth is a desirable goal. He first points out that the incomehappiness relation remains a controversial one, as the recent debate between Stevenson and Wolfers (2008) and Easterlin suggests. However, the debate about the income-happiness relationship does not resolve the question about the desirability of growth. While self-reported happiness is good, so are other things, such as autonomy, good health and safe neighborhoods. Frank argues that economic growth does, in fact, improve the human lot, because it reduces child mortality and hunger, and because it produces preconditions for political and social progress, including environmental improvements, reduction of discrimination against minorities and policies which help the poor. Evolutionary selection rewards organisms which have a high probability of survival and therefore are better able to adapt to their environments, but not necessarily happier people. People therefore adapt to the good and the bad, but that is not to say that growth is not good.

Carol Graham and Andrew Felton provide a brief review of the empirical literature on the effect of inequality on subjective well-being and then analyse in detail data from a large survey for Latin America. While some earlier studies - including Alesina et al. (2004) - suggest that inequality 
has a negative effect on happiness in the USA and Europe, not all studies confirm this. Graham and Felton find that the effect of inequality on happiness in Latin America depends on the concept of inequality used (that is, overall inequality in the country, the relative income or wealth to different reference groups and perceived status of a person, or perceptions about overall inequality or social mobility). Their results show that relative income and wealth have a positive, significant effect on happiness, supporting the relative consumption hypothesis and implying that the poor are made less happy by increasing inequality and the rich made happier. They also find that perceptions about inequality, rank and opportunity are at least as important as differences in relative income and wealth, and that inequality in Latin America is perceived as a sign of persistent advantage for the rich and disadvantage for the poor, rather than future opportunities.

An important mechanism by which income inequality can arise is discrimination. The effect of discrimination on subjective well-being and happiness, and its consequences on behavior, are examined by Arthur Goldsmith in his examination of the issue of wage discrimination by race. Their analysis starts from the fact that black workers in the USA have a lower wage than white workers of comparable background and characteristics, and from the idea that relative income is an important determinant of happiness and well-being. Using data on perceptions of discrimination they examine how workers who feel that they are discriminated against (in terms of hiring, advancement and general workplace discrimination) react to this - either by waiting to allow employers to learn about their productivity and end statistical discrimination, or by reducing their effort, or by increasing their effort. They do so by examining the impact of these reactions to wage differences between black workers who perceive discrimination, on the one hand, and black workers who do not and white workers, on the other. They find that the data are consistent with the hypothesis that black workers who are discriminated against at hiring attempt to overcome the problem by increasing effort, while those who are discriminated against in the workplace or for advancement reduce their effort.

\section{I.3 HAPPINESS AND POLITICS}

Political scientists are latecomers to the study of happiness and subjective well-being. It is one of the goals of this book to bring specifically political concerns, and more specifically still, the concerns of political science as a scholarly discipline, into the academic study of happiness. 
Thus, the contribution by Alexander Pacek provides a general summary of the extant work on the role of the political, broadly construed, as a factor determining the quality of life that citizens experience. Pacek provides a nearly encyclopedic review, cataloguing and critically evaluating the research in a way never previously attempted. As he discusses in more detail, the central areas of political inquiry relate to the role of democracy, social capital (and the governmental mechanisms thought to inhibit or promote it), the role of organized labor as an interest group capable of articulating the interests of the broad class of wage-earners in capitalist society, the size and qualitative characteristics of the welfare state (in conjunction with the social democratic, labor and other progressive parties conventionally understood as agents supportive of state efforts at income maintenance and redistribution), and, finally, the overall taxing and spending policies of governments.

Three of these topics are further addressed by contributions to this volume. Ronald Inglehart addresses what is surely the single most basic and compelling question that a political scientist might ask about wellbeing: does the institutionalization of the democratic process, and with it the concomitant civil and political liberties democracy implies, contribute to greater happiness? Perhaps surprisingly to those outside the field, this question may not have the easy answer we might expect. First, there are good reasons to wonder if democracy, so often thought of as a panacea for social problems, really lives up to the hopes we reflexively tend to invest in it. To be sure, democracy might well be valued intrinsically, as the protection against tyranny and exploitation it is synonymous with, but it does not automatically follow that democracy per se makes people's lives more rewarding. Thus Robert Lane (2000) argues that democracy increases the costs that citizens face, in both the literal and the psychological senses. Simplifying somewhat, Lane suggests that democracy may induce the same kind of anxiety and frustration that existentialists see in modern life: the individual appears, via the existence of representative institutions, to share in the responsibility for events, but at the same time feels powerless as an individual in the face of the collective outcomes over which one has no control. There is, too, the possibility that citizens may collectively make poor choices at the ballot box, politicizing decisions that are better left to the market or technocrats, with deleterious consequences for social life. Another line of argumentation, which is the immediate focus of Inglehart's work, is the direction of causality between the evidence that we do have linking democracy to greater well-being. In essence, Inglehart asks, does democracy promote satisfaction, or are satisfied citizens a necessary condition for the successful operation of democratic processes? 
Strikingly, the other political factors that appear in the list of the 'usual suspects' in happiness studies all relate to questions of political economy. That receiving the most attention has been the controversial work by Benjamin Radcliff (for example, Radcliff, 2001), suggesting that an expansive welfare state is strongly associated with higher levels of subjective appreciation of life. The fundamental argument at hand is the perennial one between, in the argot that political scientists have come to accept, that of 'markets vs politics'. We face here the two basic schools of thought in political economy: should human welfare be left primarily to a self-regulating market, with a minimalist state providing the least possible 'safety net' and the lowest possible level of government regulation of the economy in general and the labor market in particular, or should the state intervene in the market, through a program of what Radcliff (2001) calls 'emancipation' from the market through the joint mechanisms of greater regulation and a greater commitment to income maintenance? Generalizing, the debate becomes one of the overall public policy regimes that governments pursue, with the basic options remaining those available since the advent of the modern industrial economy, viz. the conventional programs of left and right.

In his chapter in this volume Pacek reviews at some length the considerable evidence in favor of the contention of Radcliff's (2001) and others that it is the program of the left that, empirically, appears to offer the surest path to the greatest good for the greatest number. The chapter by Charlotte Ridge, Tom Rice and Matthew Cherry offers a contrary view, suggesting that the apparent statistical relationship between social democratic policy regimes and happiness may neither be as theoretically coherent or as empirically robust as it may appear. As they note, arguments of the sort offered by Radcliff demand a certain amount of skepticism, given the stakes involved. As they write: 'Not only does [Radcliff] claim that life is better under one type of government than others, it makes the claim with respect to human happiness, perhaps the most meaningful measure of a good society.'

The same tension between market and politics also animates the research on the role of labor organization as an agent of human wellbeing. Political scientists rightly focus on labor unions as political institutions in a variety of respects. Unions are, first, political actors in the electoral and policy making processes, being important elements in the coalition of left and center-left parties throughout the Western world. Capitalist societies are by their very nature class societies, such that organized labor emerges as the only interest group with either the resources or the inclination to represent the interests of working-class citizens. Thus, how countries (or, in the USA, states) differ in the extent to which workers 
are organized is frequently argued to be one of the most salient features in determining their political make-ups. The strength of the labor movement is also commonly viewed as the result of the political process, in that the level of organization is largely (though by no means exclusively) determined by the legal structures that determine how readily workers can form unions. Finally, the workplace itself is an inherently political institution, and the one in which workers spend more waking hours of their lives than any other single activity. Given that the work experience affects not only one's economic well-being, but one's sense of dignity and self-respect, the institution of the labor union, as the advocate and agent of the worker in obtaining both income and dignity, has an obvious potential for affecting an individual's sense of satisfaction with life. Pacek's chapter reviews the cross-national evidence on the role of unions in fostering well-being, whereas the chapter by Suzanne Coshow and Benjamin Radcliff explores this issue further by focusing on the role of organized labor in the USA per se. They attempt to determine if the relatively modest differences in the power of organized labor across the US states appear to have equally strong effects on well-being as the larger differences across countries do. This question is especially compelling given that the national political context in the contemporary USA is one in which labor is universally regarded as a weak (and ever more progressively weak) political actor.

\section{I.4 HAPPINESS, ECONOMICS AND POLITICS}

As noted earlier, the central theme of this book is that the study of happiness is best conducted from a consciously multidisciplinary perspective. To illustrate this, the book has focused on the interaction between economics and politics in understanding happiness.

In general, there are several reasons why a multidisciplinary approach is useful. First, different disciplines have evolved in specific ways because of accidents in the development of these disciplines. Some issues have been given the label 'economic' and others the label 'political' not because they are intrinsically unrelated, but because dominant traditions within them happened to focus on them while excluding others. Second, the way that dominant traditions have separated different disciplines can also be argued to be flawed. For instance, in some popular interpretations 'economics' has focused on the operation of 'markets' and 'politics' on the operation of 'the state'. The problem with such dichotomies is that they overlook the fact that what are called 'markets' and 'the state' are intrinsically interrelated. Thus, markets do not exist in a vacuum, but are regulated by social norms and political processes, without which they 
simply cannot exist, let alone operate smoothly. Moreover, the state is deeply influenced by market processes through, for instance, their effects on income distribution, to say nothing of the dependency of the government on the 'economy' to maintain employment, its own tax revenues and, thus ultimately, the maintenance of public order. Of course, as the stock of knowledge continues expanding, specialization in areas of knowledge becomes necessary. However, it is not clear that such specialization is best done in terms of disciplines and sub-disciplines, rather than in terms of issues. Thus, we argue that it is preferable for scholars to focus on the issue of happiness, rather than simply applying the ideas of particular disciplines to the study of happiness. But given our disciplinary backgrounds, this is easier said than done. Indeed, the book is divided into separate parts which deal with economics and happiness, and with politics and happiness. However, while we are at least to some extent prisoners of our disciplines, we realized from our conference that we have much to gain in our study by struggling to break free of our disciplinary moorings.

We can illustrate this through four examples of what the chapters in the book suggest can be gained by combining the insights of economics and politics to the study of happiness. The first example concerns the concept and measurement of happiness. Economics has a long history of conceiving of happiness in terms of subjective well-being. The Utilitarians mostly thought of well-being in terms of how people evaluated their circumstances, and Easterlin's early work used evidence from happiness surveys to quantify the 'human lot'. As noted earlier, some economists, such as Sen (1999) have discussed serious problems with overemphasis on utility or subjective well-being, and advocated the use of other indicators, such as people's ability to achieve valued 'goods'. Political scientists, who seem to be overly wedded to measuring happiness using the notion of subjective well-being by using happiness surveys can do worse than take into account the warnings posed by these economists.

The second example relates to whether happiness depends on some outcomes or of some processes. Most economists entertain a consequentialist bias, evaluating well-being in terms of actual outcomes. Political scientists, however, have frequently been more interested in processes, such as whether governments are democratic, and to what extent individuals participate. To be sure, there are some economists who seem to be interested in processes - such as, for instance, those promoting the freedom of choice and the equality of opportunity and reducing economic insecurity - while, as discussed in some of the chapters in this book, some political scientists are interested in the outcomes - such as the election of left parties - on happiness. Happiness and well-being, of course, can be said to depend on both outcomes and processes, and an approach that is informed by the 
work of both economists and political scientists is more likely to recognize this.

While these two examples related to the concept and broad approach to the study of happiness, our remaining examples relate to how multidisciplinary study involving both economics and politics can improve our understanding of the determinants of happiness. The third example concerns efforts by economists to understand the determinants of happiness. If increases in income and consumption do not make people significantly happier, at least beyond a certain level, what economic choices and conditions do? Economists and other social scientists have examined the evidence to find that higher socio-economic status, lower unemployment rates, lower inflation, more economic equality (although this is somewhat controversial), the kind (that is, their intrinsic nature) of work people do, more time not spent at work and lower levels of consumer debt contribute to happiness. These findings also suggest that greater economic insecurity - the possibility of losing jobs, for instance - affect subjective well-being. Economic well-being - in terms of functioning and capabilities - is also positively affected by greater access to good health and education. Some of these determinants of happiness can be chosen by individuals, but many of these can be affected by economic conditions. Other determinants, like income distribution and unemployment, are beyond individual control. If there is some validity to these empirical findings, the question then arises: what kinds of overall economic conditions and policies are more likely to increase happiness and well-being? This, in turn, raises the question: what political factors make it more likely that these policies will actually be adopted? For instance, given that the public policies that protect workers from insecurity (through, say, unemployment insurance), or the structure of laws that make union organizing easier or more difficult, are simultaneously economic in their impact on individuals, but also the result of a political process. It is thus necessary to understand economic and political factors and their interaction to answer these questions. As the labor union example illustrates most strikingly, seemingly economic factors are often inherently political, and can only be adequately understood as political phenomena.

Fourth, and this time starting from the work done by political scientists (as Pacek's chapter reviews) suggests that the election of parties on the political left (as compared to those on the political right) increases subjective well-being. These contributions argue that this finding can be explained in terms of the economic security and social safety nets provided by such left-leaning governments However, left-leaning governments are not all the same and there is a great deal of heterogeneity about what policies they pursue. It is worthwhile for political scientists to draw on the 
work of economists to examine what specific types of policies promote economic security in any given context.

We end this section with two comments. First, although we argue that there needs to be a greater recognition of the interaction between the economic and political, and more collaborative work between economists and political scientists, we do not endorse any particular type of what has been called political economy. In particular, we do not endorse that all of this interdisciplinary work needs to follow what is called 'rational choice' approach of self-interested, optimizing agents. This approach can illuminate some issues, but we find - for instance, because of what was argued earlier about 'rationality' - that for many questions this approach can be extremely misleading. Second, although we have concentrated here on economics and politics, this argument applies to other disciplines - such as psychology, sociology, philosophy and theology - as well, as implied by several chapters in the book.

\section{I.5 TOWARD A HAPPIER WORLD?}

A final concern that must animate any study of human happiness is the obvious one of what should be done by people and societies to improve their lives, individually and collectively.

The first question is whether happiness itself is a goal that should be pursued. Despite the fact that for so many people happiness is the goal of life and the motivation for living, and the widespread acceptance of the legitimacy of this goal (as ensconced, for instance, in the US Declaration of Independence's statement that 'the life, liberty and the pursuit of happiness' are the 'inalienable rights' of people), some have questioned whether the goal is worth pursuing. Wilson (2008), for example, argues that 'happiness as immediate gratification, happiness as superficial comfort, happiness as static contentment' could well be a 'dystopia of flaccid grins' (pp. 8-9). He argues that the search for happiness is delusional and inauthentic in a world full of insecurity, and that it can lead to the destruction of a thriving culture, by removing the muse of great literature, painting, music and innovation. While Wilson's admonitions need to be taken seriously, and are closely related to Alasdair MacIntyre's insightful remarks at the conference, they do not negate the fact that it may be desirable to reduce insecurity of certain kinds for many people in an insecure world in ways that do not provide only immediate gratification through the mere accumulation of 'stuff'. Moreover, as Wilson is careful to point out, he is 'thinking only of ... [the] specific American type of happiness. I am not questioning joy in general ... [ [For instance,] I am not criticizing that slow-burning 
bliss that issues from a life spent helping those that hurt. . . . Likewise, ... I don't want to romanticize clinical depression' (Wilson, 2008, p. 7).

Even if happiness, appropriately defined, is accepted as a legitimate goal, it can be asked whether we should try to maximize happiness as a matter of public policy. In their chapter in this volume Bruno Frey and Alois Stutzer discuss whether recent advances in the measurement of happiness, especially using data from surveys which ask people to evaluate the quality of their own lives, should make societies try to maximize aggregate national happiness. Although they find that these measures improve on standard measures of evaluation like GDP, they argue that governments should not try to maximize total happiness because doing so fails to take into account the complexities of the political process, fails to take into account the fact that people adapt to their situations (perhaps being on a kind of aspirations treadmill), results in governments trying to manipulate happiness measures to suit their purposes, and induces people to misrepresent their happiness levels strategically to make policies favor them. But even if pursing the formal maximization of happiness is problematic, in Frey and Stutzer's view happiness research is valuable because it can help people make informed choices on how to best pursue their happiness (broadened to include other goods such as loyalty, self-respect, freedom and personal development) privately and collectively, and to identify institutions which help to achieve these goals.

The brief concluding chapter by Dutt and Radcliff addresses the issue of what can be done to help people lead happier and more fulfilling lives? They argue that it is necessary to take not only a multidisciplinary approach to what can be done to increase happiness and well-being, but that it is appropriate to approach this question at different levels: at the level of the individual, of groups, of nations and of the world as a whole. Individuals can do many things to make appropriate decisions. As we have previously noted, the chapter by Sheldon and Lyubomirsky examines directly how, and to what extent, individuals can act to improve the degree to which they find life rewarding. The chapter by Dutt suggests people can be happier by consuming those things which provide gains that endure rather than those things which increase their status or those things to which they quickly get habituated. However, in some cases individuals may lack the incentive to do things on their own, because the happiness they will get from their actions depends not only on what they do, but what others do. For instance, it is possible that if individuals try to work fewer hours to spend more time with family or friends, they may create the impression that they are not dependable and committed employees and possibly lose their jobs. Thus groups of workers can collectively try to reduce their working hours, and governments can impose laws to limit 
working hours which could increase happiness. But here, too, individuals with a better understanding of the determinants of happiness can make more informed choices about which policies to support. Finally, especially in an increasingly globalized world, the consequences of individual decisions for happiness and well-being may well depend on what people around the world do - the issue of global warming is an obvious example - such that achieving happiness can be seen as a truly human undertaking, not merely a personal or national one.

\section{REFERENCES}

Alesina, Alberto, Rafael Di Tella and Robert MacCulloch (2004), 'Inequality and happiness: are Europeans and Americans different?', Journal of Public Economics, 88, 2009-42.

Argyle, Michael (1987), The Psychology of Happiness, 2nd edn, 2001, London: Routledge.

Argyle, Michael (1999), 'Causes and correlates of happiness', in D. Kahneman, E. Diener and N. Schwarz (eds), Well-Being: The Foundations of Hedonic Psychology, New York: Russel Sage Foundation, pp. 353-73.

Diener. E., E.M. Suh, R.E. Lucas and H.L. Smith (1999), 'Subjective well-being three decades of progress', Psychological Bulletin, 125, 276-302.

Easterlin, Richard (1974), 'Does economic growth improve the human lot? Some empirical evidence', in Paul David and Melvin Reder (eds), Nations and Households in Economic Growth: Essays in Honor of Moses Abramovitz, Palo Alto, CA: Stanford University Press, pp. 98-125, reprinted in Easterlin (2002).

Easterlin, Richard (2001), 'Income and happiness: towards a unified theory', Economic Journal, 111, July, 465-84, reprinted in Richard Easterlin (ed.) (2002), Happiness and Economics, Cheltenham, UK and Northampton, MA, USA: Edward Elgar Publishing.

Easterlin, Richard (ed.) (2002), Happiness in Economics, Cheltenham, UK and Northampton, MA, USA: Edward Elgar Publishing.

Frank, Robert (1999), Luxury Fever. Why Money Fails to Satisfy in an Era of Excess, New York: The Free Press.

Frey, Bruno S. and Alois Stutzer (2002), Happiness and Economics, Princeton, NJ: Princeton University Press.

Lane, Robert E. (2000), The Loss of Happiness in Market Democracies, New Haven, CN: Yale University Press.

Layard, Richard (2005), Happiness. Lessons from a New Science, London: Penguin Press.

Maslow, Abraham (1954), Motivation and Personality, New York: Harper.

McMahon, Darrin M. (2006), Happiness. A History, New York: Atlantic Monthly Press.

Nettles, Daniel (2005), Happiness. The Science Behind Your Smile, Oxford: Oxford University Press.

Putnam, Robert (2000), Bowling Alone. The Collapse and Revival of American Community, New York: Touchstone Books. 
Radcliff, Benjamin. (2001), 'Politics, markets, and life satisfaction: on the political economy of human happiness', American Political Science Review, 95 (4), 939-52.

Schor, Juliet (1998), The Overspent American. Upscaling, Downshifting and the New Consumer, New York: Basic Books.

Sen, Amartya (1999), Development as Freedom, New York: Anchor Books.

Stevenson, Betsey and Justin Wolfers (2008), 'Economic growth and subjective well-being: reassessing the Easterlin Paradox', Brookings Papers on Economic Activity, 1, 1-87.

Veblen, Thorstein (1899), The Theory of the Leisure Class. An Economic Study of Institutions, New York and London: Macmillan.

Veenhoven, R. and J. Ehrhardt (1995), 'The cross-national pattern of happiness: test of predictions implied in three theories of happiness', Social Indicators Research, 43, 33-86.

Wilson, Eric (2008), Against Happiness, New York: Farrar, Straus and Giroux. 
Amitava Krishna Dutt and Benjamin Radcliff - 9781849801973 Downloaded from PubFactory at $04 / 26 / 2023$ $04: 46: 25$ AM 